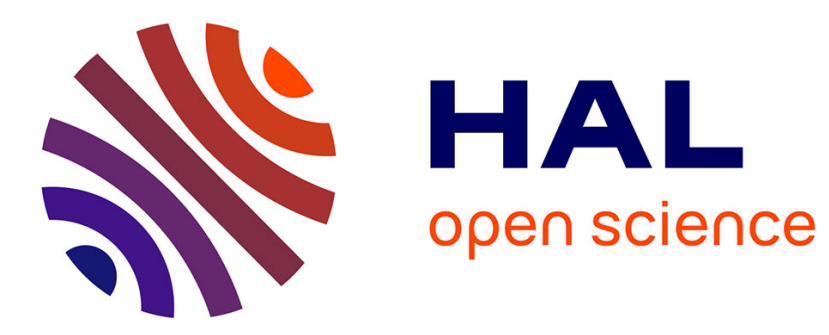

\title{
Ca-3(VO4)(2) Nanowires on Metallic CaVO3 Films as Nanocapacitors
}

Valérie Demange, Bruno Berini, Brice Gautier, Elena Popova, Yves Dumont, Arnaud Fouchet

\section{- To cite this version:}

Valérie Demange, Bruno Berini, Brice Gautier, Elena Popova, Yves Dumont, et al.. Ca-3(VO4)(2) Nanowires on Metallic CaVO3 Films as Nanocapacitors. ACS Applied Nano Materials, 2020, 3 (7), pp.6684-6692. 10.1021/acsanm.0c01136 . hal-02928615

\section{HAL Id: hal-02928615 https://hal.science/hal-02928615}

Submitted on 11 Sep 2020

HAL is a multi-disciplinary open access archive for the deposit and dissemination of scientific research documents, whether they are published or not. The documents may come from teaching and research institutions in France or abroad, or from public or private research centers.
L'archive ouverte pluridisciplinaire HAL, est destinée au dépôt et à la diffusion de documents scientifiques de niveau recherche, publiés ou non, émanant des établissements d'enseignement et de recherche français ou étrangers, des laboratoires publics ou privés. 
DOI:10.1002/XXXXXXXX

\title{
Article type: Full Paper
}

\section{$\mathrm{Ca}_{3}\left(\mathrm{VO}_{4}\right)_{2}$ Nanowires on Metallic $\mathrm{CaVO}_{3}$ Films as Nanocapacitors}

Valérie Demange ${ }^{*}$, Bruno Bérini ${ }^{2}$, Brice Gautier ${ }^{3}$,Elena Popova ${ }^{2}$, Yves Dumont ${ }^{2}$, Arnaud Fouchet $^{4 *}$

${ }^{1}$ Univ Rennes, CNRS, ISCR - UMR 6226, ScanMAT - UMS 2001, F-35000 Rennes, France

${ }^{2}$ Université Paris-Saclay, Université de Versailles Saint-Quentin, CNRS, GEMaC, 78000 Versailles, France ${ }^{3}$ Institut des Nanotechnologies de Lyon, INSA de Lyon, Université de Lyon, UMR CNRS 5270, 7, avenue, Capelle F-69621, Villeurbanne, France

${ }^{4}$ Normandie Univ, ENSICAEN, UNICAEN, CNRS, CRISMAT, 14000 Caen, France

* Corresponding author:

E-mail: valerie.demange@,univ-rennes1.fr; arnaud.fouchet@ensicaen.fr

Keywords: $\mathrm{CaVO}_{3}$, TEM, PFM, complex oxide, orthovanadate, epitaxy, nanorods

\begin{abstract}
:
As $\mathrm{Ca}_{3}\left(\mathrm{VO}_{4}\right)_{2}$ is known to be ferroelectric in bulk form at room temperature, we have investigated this material at the nanoscale and at different crystallographic orientations. In this context, self-organized $\mathrm{Ca}_{3}\left(\mathrm{VO}_{4}\right)_{2}$ nanostructures have been grown on top of conducting complex oxide $\mathrm{CaVO}_{3}(\mathrm{CVO})$ thin films deposited by pulsed laser deposition on $\mathrm{SrTiO}_{3}$ (STO) substrates presenting three crystallographic orientations (i.e. (100)STO, (110)STO and (111)STO). The growth of $\mathrm{Ca}_{3}\left(\mathrm{VO}_{4}\right)_{2}$ nanostructures occurs at high temperature and is related to the oxidation of the CVO phase. Since the nanostructures exhibit epitaxial relationships with the CVO matrix, depending on the substrate orientation, we show that particular morphologies
\end{abstract}


of nanostructures could be obtained with defined shape and orientation. Atomic force microscopy, transmission electron microscopy and electron diffraction experiments were performed to characterize the different epitaxial relationships, and electron energy loss spectroscopy measurements confirm the oxidation transformation of the vanadium nanostructure $\left(\mathrm{V}^{5+}\right)$ from the $\mathrm{CVO}$ film $\left(\mathrm{V}^{4+}\right)$. Finally, piezoforce microscopy of the different nanostructures shows a non-zero piezoresponse, with in particular a clear piezoelectric activity for one type of orientation (i.e. $\left.[5 \overline{5} 4] \mathrm{Ca}_{3}\left(\mathrm{VO}_{4}\right)_{2}\right)$ on (110)STO). In addition to the study of $\mathrm{Ca}_{3}\left(\mathrm{VO}_{4}\right)_{2}$ nanostructures, a complete investigation of the different domains of orthorhombic CVO film has been conducted for the three orientations. This oxidation process is particularly innovative and can lead to a way of synthesis of nanocapacitors in single step process.

\section{Introduction}

Complex oxides have been widely studied these last decades due to their functional properties like high $T_{c}$ superconductivity, ferroelectricity, ferromagnetism... Furthermore, interesting artificial multiferroicity can be generated by the growth of superlattices where different materials can be coupled at the interfaces. Another innovative way of engineering materials is to create new artificial structures with the self-organization or bottom-up approach ${ }^{1}$. Whereas this approach has received a lot of attention these last years for semiconducting nanostructures, only a few studies have been reported for complex oxides. In this context, we studied the growth of $\mathrm{Ca}_{3}\left(\mathrm{VO}_{4}\right)_{2}$ nanostructures on $\mathrm{CaVO}_{3}(\mathrm{CVO})$ thin films. $\mathrm{Ca}_{3}\left(\mathrm{VO}_{4}\right)_{2}$ in bulk form is non-centrosymmetric and has been reported to be a high-temperature ferroelectric ${ }^{2}$. Furthermore, $\mathrm{CVO}$ is a paramagnetic conductor with a $\mathrm{V} 3 d^{1}$ configuration $\left(\mathrm{V}^{4+}\right)$. CVO is especially promising as a transparent electrode due to the strong electron-electron interaction in this material ${ }^{3}$. Therefore, the bottom-up approach is particularly interesting for spontaneous 
nanocapacitors design. These $\mathrm{Ca}_{3}\left(\mathrm{VO}_{4}\right)_{2}$ nanostructures appear at the surface of $\mathrm{CVO}$ at high temperature (namely $700^{\circ} \mathrm{C}$ ). This behavior has also been observed for the archetype material based on vanadium $\mathrm{SrVO}_{3}(\mathrm{SVO})$ and is related to an oxidation process of the vanadium from $\mathrm{V}^{4+}$ to $\mathrm{V}^{5+}$ at the surface of the film. ${ }^{4,5}$ Nevertheless, a non-stoichiometry at the surface of the perovskite with a slight excess of $\mathrm{Sr}$ seems to be necessary in order to obtain these nanostructures ${ }^{6}$. In bulk form, phase equilibria in the system $\mathrm{SrO}-\mathrm{V}_{2} \mathrm{O}_{5}$ can give the different phases from $\mathrm{SVO}, \mathrm{Sr}_{3} \mathrm{~V}_{2} \mathrm{O}_{8}$ to $\mathrm{Sr}_{2} \mathrm{~V}_{2} \mathrm{O}_{7}$. The different processes of reduction or oxidation have been investigated and these different phases can be obtained at specific temperature and oxygen pressure values ${ }^{8-10}$. In the case of calcium vanadate, Garcia-Jaca et al. have reported the synthesis, via the thermal decomposition of a metallo-organic precursor at $800^{\circ} \mathrm{C}$, of nonstoichiometric $\mathrm{CaVO}_{3+\delta}$, which has a mixed oxidation state $\mathrm{V}^{4+} / \mathrm{V}^{5+}$. X-ray diffraction pattern of this compound annealed $4 \mathrm{~h}$ in air at $900^{\circ} \mathrm{C}$ displays minor peaks of the $\mathrm{Ca}_{3}\left(\mathrm{VO}_{4}\right)_{2}$ phase ${ }^{11}$. In thin film form, some nanostructures also appears at the surface of $\mathrm{CaVO}_{3}$ and particularly when the perovskite phase is slightly richer with $\mathrm{Ca}^{12}$. It was previously shown that SVO transforms on oxidation into $\mathrm{Sr}_{3} \mathrm{~V}_{2} \mathrm{O}_{8}$ and $\mathrm{SrV}_{6} \mathrm{O}_{11}{ }^{13}$. Nevertheless, there is no similar phase to $\mathrm{SrV}_{6} \mathrm{O}_{11}$ with the same type of structure in the $\mathrm{Ca}-\mathrm{V}-\mathrm{O}$ system. Therefore, a possible oxidation reaction from the $\mathrm{CVO}$ oxidation process: is:

$3 \mathrm{CaVO}_{3}+\frac{3}{4} \mathrm{O}_{2} \rightarrow \mathrm{Ca}_{3} \mathrm{~V}_{2} \mathrm{O}_{8}+\frac{1}{2} \mathrm{~V}_{2} \mathrm{O}_{5}$

In this report, we are studying how orientation, shape and morphology of $\mathrm{Ca}_{3}\left(\mathrm{VO}_{4}\right)_{2}$ nanostructures can be controlled at the nanoscale on the surface of metallic strongly correlated CVO. In this context, we tuned the orientation of the $\mathrm{Ca}_{3}\left(\mathrm{VO}_{4}\right)_{2}$ nanostructures by deposition of the CVO films on $\mathrm{SrTiO}_{3}$ substrates with the orientations (100), (110) and (111) as shown in figure 1 . 
Growth of $\mathrm{CaVO}_{3}$ film (electrode) by

Pulsed Laser Deposition

cVo

100 STO, 110 STO or 111 STO substrate
Annealing at $760^{\circ} \mathrm{C}$ for $60 \mathrm{~min}$

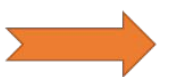

100 STO

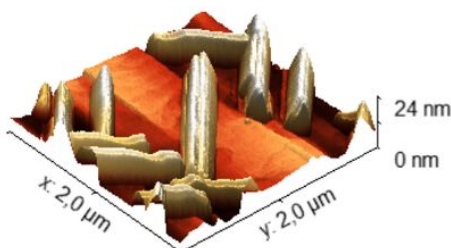

110 STO

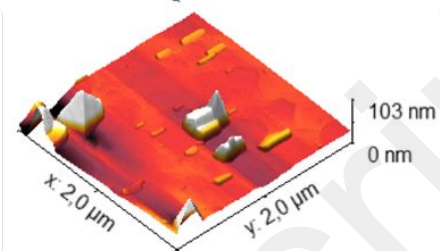

111 STO

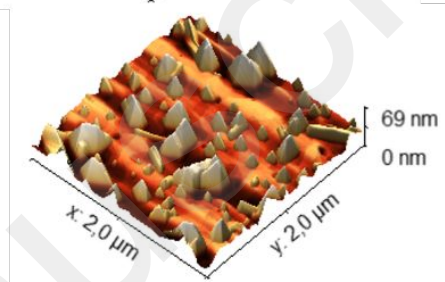

Figure 1. a) Schematic representation of the preparation of the $\mathrm{CaVO}_{3}$ thin film by PLD used as electrode and the spontaneous formation of the $\mathrm{Ca}_{3}\left(\mathrm{VO}_{4}\right)_{2}$ nanostructures after annealing of the samples. Those nanostructures present a non-centrosymmetric space group and can be used as nanocapacitors.

The samples were investigated by X-ray (XRD) and electron diffraction, transmission electron microscopy (TEM), electron energy loss spectroscopy (EELS) and local probe microscopy in order to observe the morphology, epitaxial relation, orientation and properties of these nanostructures. Finally by using piezoforce microscopy (PFM), we demonstrate at nanoscale that piezoelectric behavior of $\mathrm{Ca}_{3}\left(\mathrm{VO}_{4}\right)_{2}$ depends on the crystallographic orientation.

\section{Methods Experimental Section}

\subsection{Synthesis of CVO films}

We used the pulsed laser deposition technique with a $\operatorname{KrF}$ excimer laser $(\lambda=248 \mathrm{~nm})$ with an energy density of $1.85 \mathrm{~J} / \mathrm{cm}^{2}$ and $2 \mathrm{~Hz}$ repetition rate. Thin films were grown on single- 
crystal (SurfaceNet GmbH) (100), (110) and (111) STO both sides polished substrates $(10 \times 10$ $\times 0.5 \mathrm{~mm}^{3}$ ) placed at $5 \mathrm{~cm}$ opposite to a ceramic CVO target. The deposition temperature was $760^{\circ} \mathrm{C}$ with partial oxygen pressure fixed at $1.2 \times 10^{-4} \mathrm{~Pa}$. Film thicknesses of $86 \mathrm{~nm}$ have been determined by conventional step-meter measurements (Bruker Dektak 8) and confirmed by Laue oscillations as seen by XRD of CVO films grown on the (100)STO substrate. The nanostructures were directly obtained by maintaining the deposition atmosphere during the cooling stage and their sizes were controlled by keeping the sample at high temperature during 60 min after the growth.

\subsection{Characterizations}

Near field experiments were carried out with a Bruker AFM (Dimension 3100). Acquisitions of topology have been done under ambient conditions. A vibration-free table was employed to eliminate ground vibration and acoustic noise. In order to well-define the morphology of the nanostructured surface, the AFM tapping-mode was used with a resolution of $512 \times 512$ pixels. In this topography mode, a silicon tip (MPP11-100) with a nominal tip radius of $<10 \mathrm{~nm}$ was employed. Piezoresponse Force Microscopy (PFM) has been extensively used to map ferroelectric domains in thin films and single crystals. It is based on piezoelectric converse effect where an applied voltage induces a deformation of the sample. During PFM experiments, an alternating voltage was applied between the back electrode of the sample and the AFM metal-coated tip (which plays the role of the top electrode), while the resulting motion of the tip was recorded through the analysis of the photodiode signal by a lock-in amplifier providing the amplitude of the signal and its phase which allow to evaluate the piezoelectric activity and the orientation of the domains in ferroelectric films. In order to increase the signal to noise ratio, Dual Frequency Resonant Tracking (DFRT) was used with typical contact 
resonance frequencies in the $300-350 \mathrm{kHz}$ range (PtIr coated tips). In this work, only vertical PFM was implemented, i.e. only the out of plane polarization was probed. PFM experiments were carried out with a NT-MDT AFM instrument equipped with an external Zürich Instruments HF2LI Lock-in amplifier allowing to implement DFRT. X-ray diffraction (XRD) analysis of thin films was carried out using a $\theta-2 \theta$ instrument (Bruker AXS D8 Advance) working with a monochromatized $\mathrm{Cu} \mathrm{K} \alpha 1$ radiation and equipped with a $1 \mathrm{D}$ detector (192 channels). Data were collected using a $0.008^{\circ}$ step. Fit of XRD fringes was performed by using the InteractiveXRDFit software ${ }^{14}$. Transmission electron microscopy (TEM) study on the CVO films grown on (100), (110) and (111)STO was performed by using a Jeol 2100 instrument operating at $200 \mathrm{kV}$ and equipped with an energy dispersive X-ray spectrometer (EDXS, Oxford Aztec $80 \mathrm{~mm}^{2}$ SDD device), and Gatan Orius 200D and Gatan US Scan 1000 cameras. Samples for TEM were obtained by scratching the film by a diamond tip and obtained fractions were collected on a commercial carbon-coated copper microgrid. Electron energy loss spectroscopy (EELS) and energy-filtered TEM-spectrum imaging (EFTEM-SI) were performed by using a Gatan Imaging Filter ER device. EELS spectra were recorded with an energy resolution of $0.6 \mathrm{eV}$, a dispersion of $0.05 \mathrm{eV} /$ channel and a camera length $\mathrm{L}=6 \mathrm{~cm}$ and were corrected of plural inelastic scattering contribution after background subtraction. EFTEMSI data were collected in the range 505-540 eV with an energy slit width of $1 \mathrm{eV}$ and an energy step of $1 \mathrm{eV}$ for each energy plane. After removal of X-rays hits and correction of spatial drift, multiple linear least squares (MLLS) fitting was performed by using the Gatan Digital Micrograph software to extract chemical shift maps of $\mathrm{V}^{4+}\left(\mathrm{CaVO}_{3}\right.$ phase $)$ and $\mathrm{V}^{5+}$ state $\left(\mathrm{Ca}_{3}\left(\mathrm{VO}_{4}\right)_{2}\right.$ phase $)$. 


\section{Results and discussion}

\subsection{Growth of CVO and nanostructures on (100)STO}

Figure 2a displays the XRD patterns of the CVO films grown on (100)STO. The peaks of the substrate and film are present on the diffraction pattern and no supplementary peaks associated to the $\mathrm{Ca}_{3}\left(\mathrm{VO}_{4}\right)_{2}$ nanostructures are observed (see fig. S1 for the full-range scans). This is probably due to the too small diffraction volume of the nanostructures. The perovskite CVO is orthorhombic (Pnma, $a=5.3171 \AA ; b=7.5418 \AA ; c=5.3396 \AA$ with pseudo-cubic lattice: $a_{\mathrm{pc}}=a / \sqrt{2}=3.759 \AA ; b_{\mathrm{pc}}=b / 2=3.771 \AA ; c_{\mathrm{pc}}=c / \sqrt{2}=3.775 \AA ;$ Joint Committee on Powder Diffraction Standards (JCPDS) 01-089-8654) ${ }^{15}$. In the following, only the orthorhombic setting will be used. CVO has grown on (100)STO with [020] and/or [101] preferential orientation. It is not possible to distinguish these two orientations at this stage, because the associated reflections are located at the same $2 \theta$ value (according to the JCPDS file, $2 \theta_{020 / 101}=23.594^{\circ}$ ). Laue oscillations can be observed that are arising from film thickness (previously evaluated as $86 \mathrm{~nm}$, see above). Fit of these oscillations leads to a calculated thickness of $85.7 \mathrm{~nm}$. The pseudo-cubic out-of-plane lattice constant extracted from the XRD data is $3.754 \AA$, which is smaller than the $a_{\mathrm{pc}}$ value of the bulk. The reduction of the lattice parameter can be interpreted as a tensile strain imposed by the STO substrate (lattice constant $3.905 \AA$ ) which induces a lattice mismatch of $3.86 \%$. Liberati et al. ${ }^{16}$ observed a similar result $\left(\mathrm{a}=3.75 \AA\right.$ ) for films with thickness ranging from 40 to $60 \mathrm{~nm}$ while $\mathrm{Gu}$ et al. ${ }^{17}$ observed a fully relaxed $62 \mathrm{~nm}$-thick thin film. 

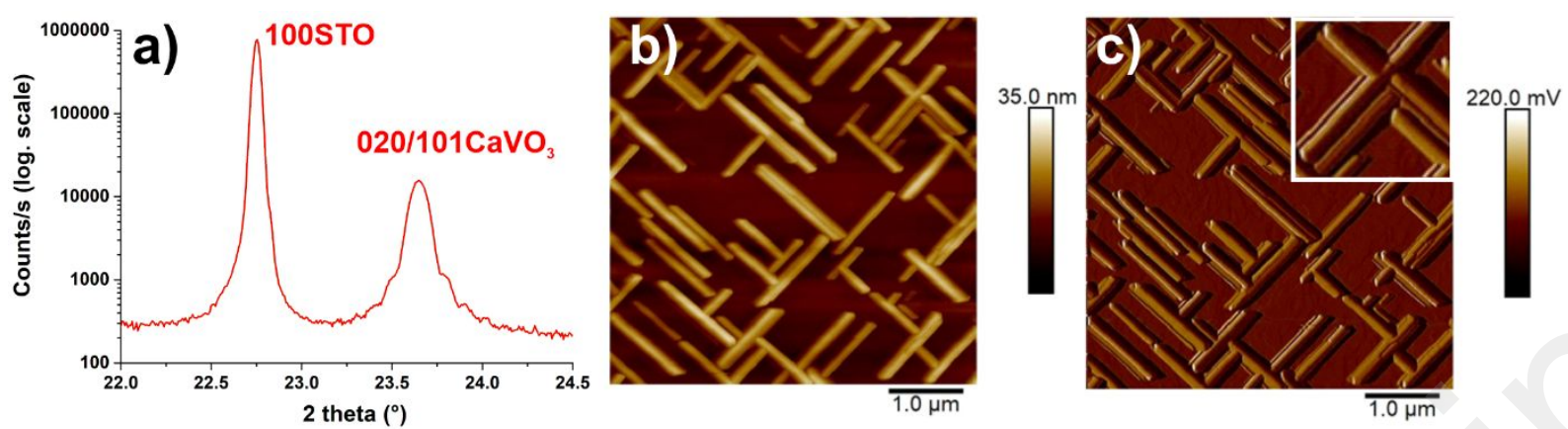

Figure 2. a) XRD patterns of CVO films grown on (100)STO. b) $5 \mu \mathrm{m} \times 5 \mu \mathrm{m}$ AFM morphology images of the film grown on (100)STO. c) $5 \mu \mathrm{m} \times 5 \mu \mathrm{m}$ AFM derivative topography image of the same area. Inset: magnified area.

The surface morphology characterized by AFM, is not smooth due to the presence of the $\mathrm{Ca}_{3}\left(\mathrm{VO}_{4}\right)_{2}$ nanostructures (figure $2 \mathrm{~b}$ ). Some elongated nanowires with length between 1 and $2 \mu \mathrm{m}$ and width between 80 to $100 \mathrm{~nm}$ appear on the surface. The nanostructure height is around $15 \mathrm{~nm}$ and two families of nanowires are present which are perpendicular to each other. In order to understand the different epitaxial relationships, TEM measurements have been performed for the CVO film and the nanostructures. Figure 3a shows a TEM bright field micrograph of a fragment of the CVO film grown on (100)STO. First, we analysed the microstructure of the CVO film. 


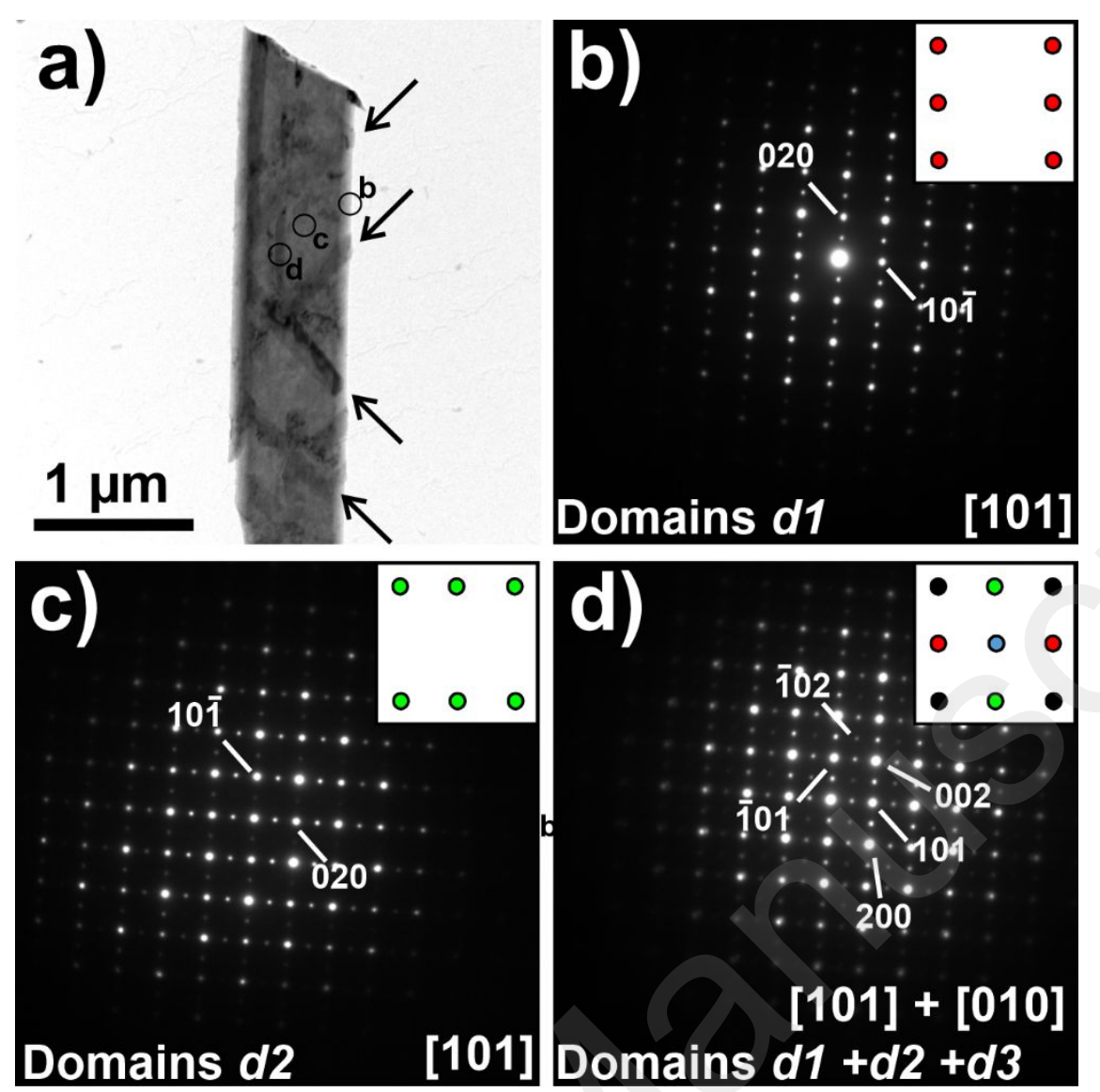

Figure 3. a) Bright field micrograph of the CVO film. Some of the nanostructures grown on CVO are depicted by arrows. b) EDP along the [101] zone axis of the CVO film (domain $d 1$ ) taken in the area labeled b in figure 3a. Inset: scheme of the pattern. c) EDP of an area close to the one shown in fig. 3b (area labeled c in fig. 3a), corresponding to a $90^{\circ}$ in-plane rotated domain (domain $d 2$ ). Inset: scheme of the pattern. d) EDP of another close area showing the presence of a $90^{\circ}$ out-of-plane rotated domain (domain $d 3$, area labeled $\mathrm{d}$ in fig. 3a). Inset: scheme of the pattern resulting of the presence of the 3 domains (black: common reflections; red: $d 1$, green: $d 2$; blue: $d 3)$.

Three selected area electron diffraction patterns (EDPs) of the CVO perovskite, obtained from the same film fragment (figures $3 b-d$ ), indicate the coexistence of three domains in the film. The patterns shown in figure $3 \mathrm{~b}$ and $3 \mathrm{c}$ were recorded along the [101] zone axis of the orthorhombic CVO perovskite. These patterns are $90^{\circ}$ in-plane rotated with respect to each other, indicating the presence of two $90^{\circ}$ in-plane domains in the perovskite film, denoted $d 1$ and $d 2$ domains in figure 3. Growth of these domains arises from the slight difference between 
the pseudo-cubic lattice parameters $a_{\mathrm{pc}}\left(c_{\mathrm{pc}}\right)$ and $b_{\mathrm{pc}}$ of the CVO phase (see schemes in fig. S2a). Finally, in some areas, one can observe EDP (fig. 3d) with additional reflections corresponding to the growth of a third domain (domain $d 3$ ) arising from the slight difference between $a_{\mathrm{pc}}$ and $c_{\mathrm{pc}}$, and corresponding to a $90^{\circ}$ rotation relative to the out-of-plane direction (fig. S2a). In these three EDPs, some reflections (as $0 k 0, k$ odd, in fig. $3 \mathrm{~b}, \mathrm{c}$, and $h 00, h$ odd and $00 l, l$ odd, in fig.3d), that should be extinct, are actually visible due to classical double diffraction phenomena coming from strong dynamic effects of electron diffraction.

Schemes of these 3 domains in the real space are drawn along the preferential growth direction (see figure S3) and in-plane view orientation showing the $\mathrm{VO}_{6}$ octahedra orientation relatively to those of the substrate. These schemes display the 3 possible pseudo-cubic octahedra arrays leading to cube on cube epitaxy on (100)STO. The presence of these three different variants is explained by the small difference, along the different directions, of the lattice mismatches defined as $\left(a_{\mathrm{STO}}-a_{f}\right) / a_{\mathrm{STO}} \times 100$, where $a_{\mathrm{STO}}$ is the STO lattice parameter and $a_{f}$ is the film lattice parameter. Domains $d 1$ and $d 2$ have a lattice mismatch of $3.51 \%$ and $3.43 \%$ with STO, respectively, while the mismatch of domain $d 3$ with the substrate is equal to $3.51 \%$ in both directions. Presence of different domains have also been observed for CVO films grown on (001) $\mathrm{LaSrAlO}_{4}$ substrate $^{12}$ and also for other orthorhombic perovskites (such as $\mathrm{YFeO}_{3}$ and $\mathrm{PrVO}_{3}$ ) grown on cubic substrates ${ }^{18,19}$. 

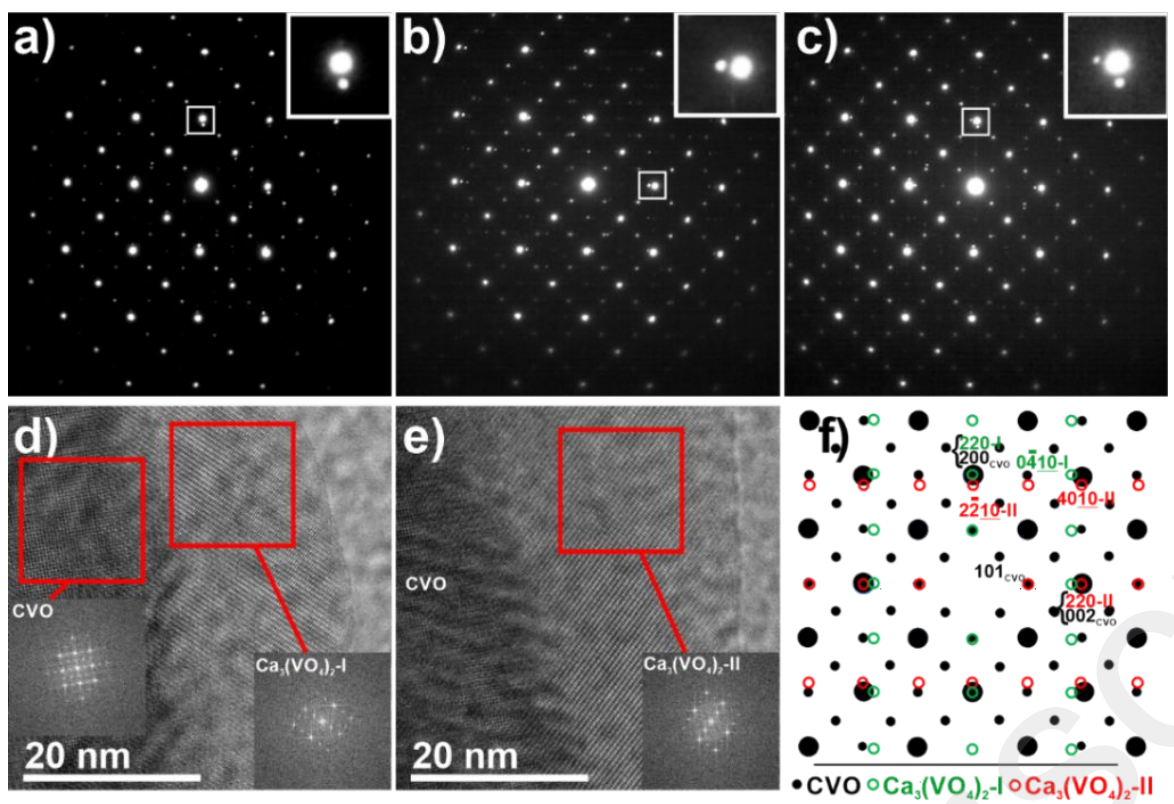

Figure 4. EDPs of the CVO film along the [010] zone axis displaying additional reflections due to the elongated nanostructures, as those depicted by white squares in the patterns and magnified in the insets. The pattern a) corresponds to an area in which the first variant of nanostructure is present, the pattern b) corresponds to the second variant, and the pattern c) presents reflections of both variants. d) and e) High resolution TEM images (HRTEM) of two different $\mathrm{Ca}_{3}\left(\mathrm{VO}_{4}\right)_{2}$ variants (on the right of the image) on CVO (on the left). Insets: Fast Fourier Transform (FFT) patterns of the corresponding areas surrounded in red. The corresponding FFT pattern is rotated of $90^{\circ}$ between d) and e), in agreement with electron diffraction pattern displayed in a) and b). f) Scheme of the EDP displayed in c) with reflections of CVO film (black dots), and those of the two $\mathrm{Ca}_{3}\left(\mathrm{VO}_{4}\right)_{2}$ variants (green and red).

Figure 4 displays EDPs along the [010] zone axis of CVO (domain $d 3$ ) on which additional reflections (see insets) due to the elongated nanostructures are present (same results were observed for the two other zone axis of $\mathrm{CVO}$ ): the pattern in fig. $4 \mathrm{a}$ corresponds to the crystals elongated in a given direction (see the small darker bands in figure $3 \mathrm{a}$ ), while the pattern in fig. $4 \mathrm{~b}$ corresponds to a second family of nanostructures that are rotated by $90^{\circ}$ relatively to the first variant of crystals (as seen by AFM in fig. 2b). Fig. 4c is a pattern in which both variants contribute. These additional reflections form rectangular patterns that are schemed in figure $4 \mathrm{f}$ 
in green for one variant and in red for the other one. These patterns are indexed by considering the [ $\overline{5} 52]$ zone axis of the orthovanadate $\mathrm{Ca}_{3}\left(\mathrm{VO}_{4}\right)_{2}$ phase $(R 3 c, a=10.8 \AA, c=38.2 \AA$, JCPDS 00-019-0259 $)^{20}$. For both variants, the 110 reflections coincide with the 001 reflections of the CVO phase, while the $(1 \overline{1} 5)_{\mathrm{Ca} 3(\mathrm{VO} 4) 2}$ planes are parallel to the $\{100\}_{\mathrm{CVO}}$ planes (see figure $4 \mathrm{f}$ ) leading to the following epitaxial relationships:

$[\overline{5} 52] \mathrm{Ca}_{3}\left(\mathrm{VO}_{4}\right)_{2} / /[010] \mathrm{CVO}$

$(110) \mathrm{Ca}_{3}\left(\mathrm{VO}_{4}\right)_{2} / /(001) \mathrm{CVO}$

$(1 \overline{15}) \mathrm{Ca}_{3}\left(\mathrm{VO}_{4}\right)_{2} / /(100) \mathrm{CVO}$

The epitaxy of the nanostructures is therefore due to the fact that the lattice distances $d_{001}^{\mathrm{CVO}}=5.34 \AA$ and $d_{110}^{\mathrm{Ca} 3(\mathrm{VO} 4) 2}=5.405 \AA$ are close. Along the other direction, the lattice distances are $d_{100}^{\mathrm{CVO}}=5.317 \AA$ and $d_{1-15}^{\mathrm{Ca} 3\left(\mathrm{VO}^{2}\right)}=5.903 \AA$, respectively. The mismatches between $\mathrm{CVO}$ and $\mathrm{Ca}_{3}\left(\mathrm{VO}_{4}\right)_{2}$ are equal to $-1.22 \%$ for the first in-plane direction and $-11.02 \%$ for the second one. A representation in the real space of both phases projected along the [010] zone axis for CVO and [552] zone axis for $\mathrm{Ca}_{3}\left(\mathrm{VO}_{4}\right)_{2}$, respectively, is shown in Figure 5a. The red squares drawn on both schemes highlight the coincidences between the lattices. It appears that, along this orientation, the $\mathrm{Ca}_{3}\left(\mathrm{VO}_{4}\right)_{2}$ phase presents a pseudo-square lattice, leading to its epitaxy on CVO, that itself is epitaxially grown on (100)STO. These results are in perfect agreement with to that observed for the growth of $\mathrm{Sr}_{3} \mathrm{~V}_{2} \mathrm{O}_{8}$ nanostructures on (100) $\mathrm{SrVO}_{3}{ }^{4,21}$. The structure of the orthovanadate $\mathrm{Sr}_{3} \mathrm{~V}_{2} \mathrm{O}_{8}(R \overline{3} m, a=5.619 \AA, c=20.1 \AA \text {, centro-symmetric })^{22}$ is closely related to that of $\mathrm{Ca}_{3}\left(\mathrm{VO}_{4}\right)_{2}(R 3 c, a=10.8 \AA, c=38.2 \AA$, non-centrosymmetric) with a ratio between their respective lattice constants close to 2 . 


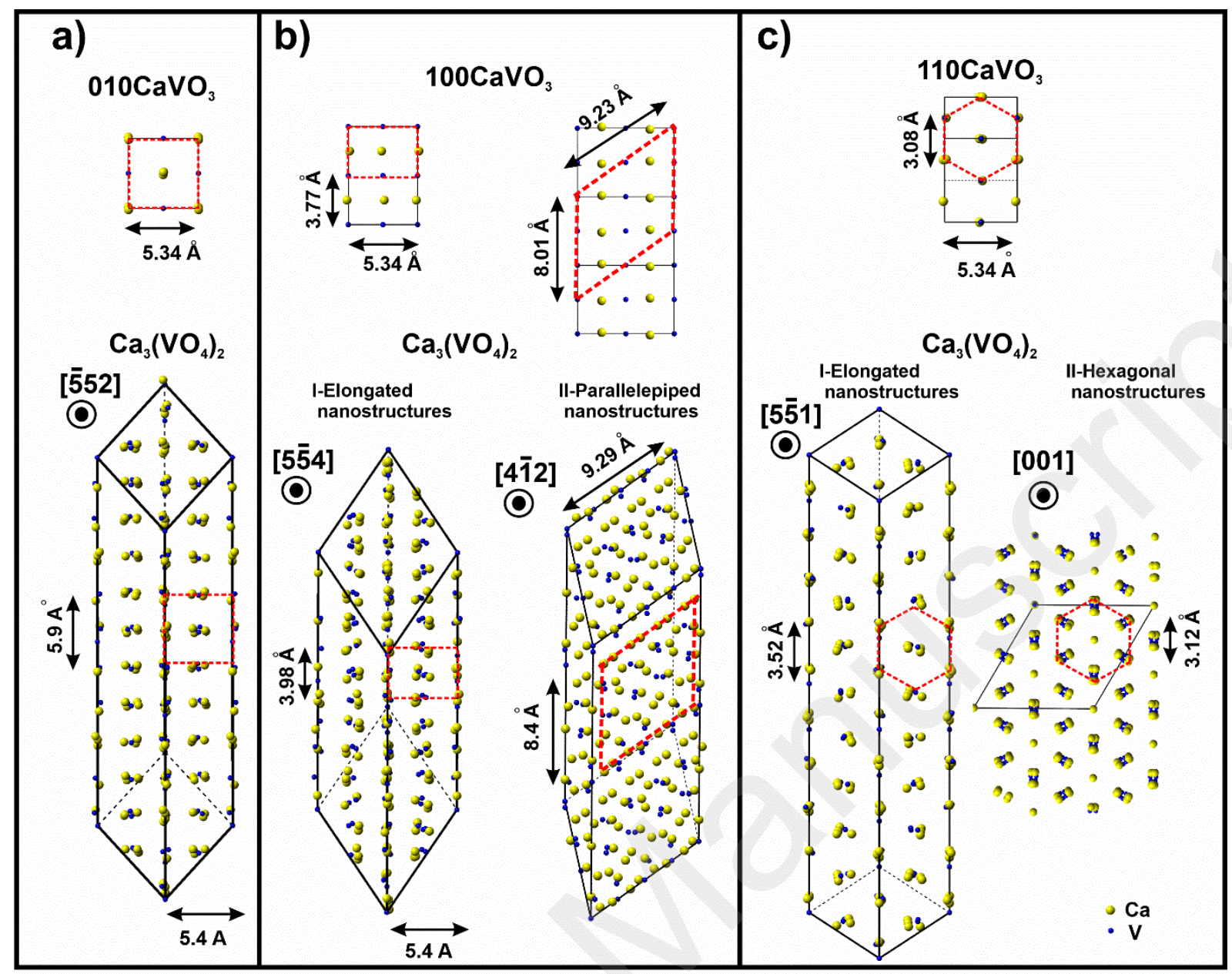

Figure 5. Schemes of the in-plane projection views of the $\mathrm{CVO}$ and $\mathrm{Ca}_{3}\left(\mathrm{VO}_{4}\right)_{2}$ structures grown on (a) (001)STO, (b) (110)STO and (c) (111)STO accordingly to the results of electron diffraction experiments. The inplane coincidence cell for both phases is displayed by dashed red lines for each orientation.

Finally, in order to characterize single nanostructure crystals, high resolution transmission electron microscopy (HRTEM) was performed on an edge of a CVO film fragment, where parts of the $\mathrm{Ca}_{3}\left(\mathrm{VO}_{4}\right)_{2}$ crystals are observed without the subjacent film. Figures $4 d$,e display HRTEM micrographs of $\mathrm{Ca}_{3}\left(\mathrm{VO}_{4}\right)_{2}$ crystals of the two variant types, showing lattice fringes where no crystalline defect can be observed. The Fast Fourier Transform (FFT) for each lattice is shown in the insets. These patterns are identical but are in-plane rotated by $90^{\circ}$ and correspond to the [552] zone axis of the $\mathrm{Ca}_{3}\left(\mathrm{VO}_{4}\right)_{2}$ phase, in agreement with the EDP pattern shown in figure 4f. The FFT of the CVO film located on the left of the HRTEM 
image is also displayed. Comparison of FFTs fully confirms the epitaxial relationships determined by electron diffraction.

In order to confirm the valence state of the vanadium during the self-formation of the nanostructures, electron energy loss spectra (EELS) measurements were performed. Figure S4 shows the EELS spectra of the CVO film and of a $\mathrm{Ca}_{3}\left(\mathrm{VO}_{4}\right)_{2}$ nanostructure. These spectra show both vanadium $\mathrm{L}$ and oxygen $\mathrm{K}$ edges that are close in the energy scale. The CVO $\left(\mathrm{V}^{4+}\right)$ spectrum is fully similar to the one reported by Fitting Koukouris et al. ${ }^{23}$. Furthermore, $\mathrm{Ca}_{3}\left(\mathrm{VO}_{4}\right)_{2}$ phase shows two maxima in the $\mathrm{V} \mathrm{L} 3$ edge, similarly to $\mathrm{V}_{2} \mathrm{O}_{5}{ }^{24}, \mathrm{LaVO}_{4}{ }^{23}$ and $\mathrm{Sr}_{3} \mathrm{~V}_{2} \mathrm{O}_{8}{ }^{21}$ oxides for which the vanadium possesses formally the $\mathrm{V}^{5+}$ valence state. In these references, the difference in energy positions between the two maxima is approximatively 1.5 , 1.8 and $2.1 \mathrm{eV}$ for $\mathrm{V}_{2} \mathrm{O}_{5}, \mathrm{LaVO}_{4}$ and $\mathrm{Sr}_{3} \mathrm{~V}_{2} \mathrm{O}_{8}$, respectively. For the $\mathrm{Ca}_{3}\left(\mathrm{VO}_{4}\right)_{2}$ phase, this difference is $2 \mathrm{eV}$. Chemical state mapping of the $\mathrm{V}^{4+}$ and $\mathrm{V}^{5+}$ states has been obtained by using energy-filtered TEM spectrum imaging technique (EFTEM-SI). From the experimental EFTEM-SI data cube, the reference spectra for the pure $\mathrm{V}^{4+}$ and $\mathrm{V}^{5+}$ states were extracted and were used for multiple linear least squares (MLLS) fitting to map the V state in an area of the sample. Figures S4b,c display the spatial distribution of the $\mathrm{V}^{4+}$ and $\mathrm{V}^{5+}$ state, and figure $\mathrm{S} 4 \mathrm{~d}$ shows the resulting EFTEM map for $\mathrm{V}$ states. The spatial distribution of the $\mathrm{V}^{5+}$ state in this map corresponds to the different nanostructures (in red) that are present in this area, while the spatial distribution of the $\mathrm{V}^{4+}$ state fits the subjacent CVO film (in green).

We did not observe $\mathrm{V}_{2} \mathrm{O}_{5}$ or any other phase by any of the characterization techniques. This is possibly due to their small amount and their dispersion, or because these phases are nonepitaxially grown. For instance, Moreno et al. have reported the formation of 60-300 nm wide La-Sr-O islands emerging at the surface of $\mathrm{LaSrMnO}_{3}$ films while a secondary phase, namely $\mathrm{Sr}_{3} \mathrm{Mn}_{2} \mathrm{O}_{7}$, is embedded in the films as $10-20 \mathrm{~nm}$ inclusions, therefore not visible at the film surface $^{25}$. 


\subsection{Growth of CVO and nanostructures on (110)STO}

Figure 6a displays the XRD patterns of the CVO films grown on (110)STO, showing that CVO has grown on (110)STO with (002) and/or (200) preferential orientations $\left(2 \theta_{002}=\right.$ $33.598^{\circ} ; 2 \theta_{200}=33.685^{\circ}$ ) (note that the shoulder located at the right of the substrate peak arises from defects in the substrate; indeed, the same shoulder is observed when the substrate is analyzed without the film). The pseudo-cubic out-of-plane lattice constant extracted from the XRD data is $3.753 \AA$, which is again smaller than for the bulk material and indicative of a tensile strain imposed by the substrate.

The AFM image (see fig. 6b) shows two families of nanostructures with different morphologies: the first one is elongated along an unique direction with a length of 300 to 700 $\mathrm{nm}$ and a height of $10 \mathrm{~nm}$ and the second one corresponds to some parallelepipeds with 300 to $700 \mathrm{~nm}$ square based with a height of $80-100 \mathrm{~nm}$. The derivative topography of the same area shows that this second morphology corresponds to four-fold facetted pyramids (figure 6c).
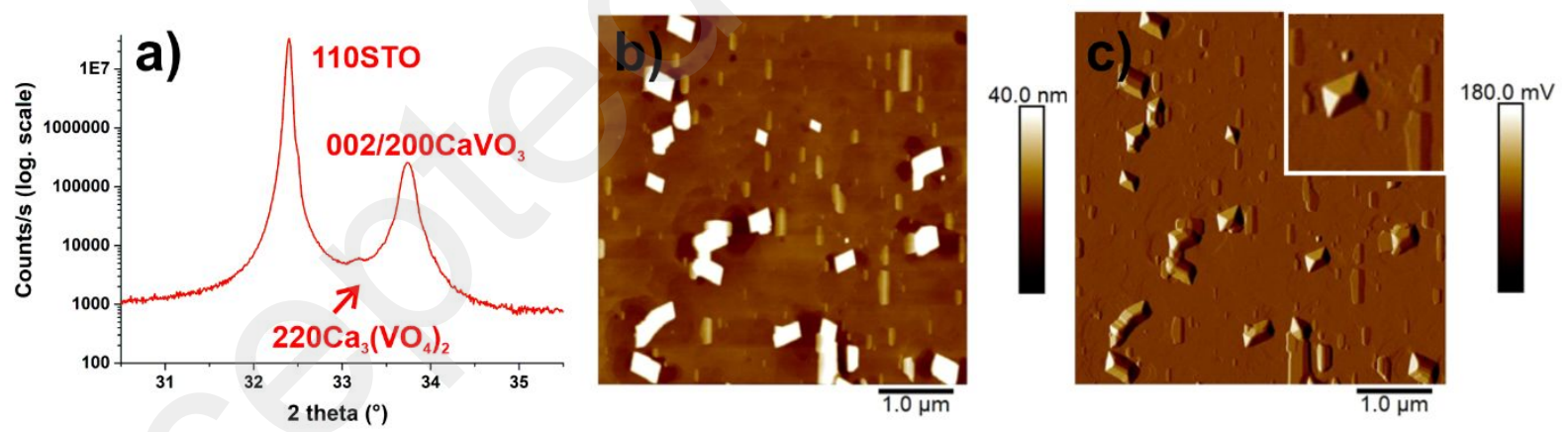

Figure 6. a) XRD patterns of CVO films grown on (110)STO (arrow shows $\mathrm{Ca}_{3}\left(\mathrm{VO}_{4}\right)_{2}$ Bragg peak). b) $5 \mu \mathrm{m} x$ $5 \mu \mathrm{m}$ AFM morphology images of the film grown on (110)STO. c) $5 \mu \mathrm{m}$ x $5 \mu \mathrm{m}$ AFM derivative topography image of the same area. Inset: magnified area.

To understand the presence of the two types of nanostructures, their epitaxial relationships were investigated by electron diffraction. Figure 7a displays the EDP taken along 
the surface normal of the CVO films grown on (110)STO. As for the film grown on (100)STO, the epitaxial CVO layer presents different variants. On (110)STO, the CVO film grows along the two out-of-plane [100] and [001] directions in reason of the small difference between $a_{p c}$ and $c_{p c}$ (fig. S2b and fig. S5), leading to the formation of $180^{\circ}$ domains, as indicated in the EDP. The mismatches between CVO and STO are equal to $\left(\mathrm{d}_{100}^{\mathrm{STO}}-\mathrm{d}_{010}^{\mathrm{CVO}}\right) / \mathrm{d}_{100}^{\mathrm{STO}}=3.43 \%$ and $\left(\mathrm{d}_{110}^{\mathrm{STO}}-\right.$ $\left.\mathrm{d}_{001}^{\mathrm{CVO}}\right) / \mathrm{d}_{110}^{\mathrm{STO}}=3.71 \%$ for the first domain, and 3.43 as above and $\left(\mathrm{d}_{110}^{\mathrm{STO}}-\mathrm{d}_{100}^{\mathrm{CVO}}\right) / \mathrm{d}_{110}^{\mathrm{STO}}=3.3 \%$ for the second one.

Some reflections that should be extinct are actually visible due to the double diffraction phenomena. Moreover, additional reflections due to the nanostructures are also observed (encircled in figure 7a). A slight tilt of the EDP displayed in fig. 7a allows to clearly see these reflections, that corresponds to the pattern of the $\mathrm{Ca}_{3}\left(\mathrm{VO}_{4}\right)_{2}$ phase along the [55 4$]$ zone axis. Furthermore, the angle between this zone axis and the (110) planes of the nanostructure is $90^{\circ}$, therefore, these planes can be observed on XRD Bragg-Brentano configuration. In fact, the corresponding 220 peak is observed in the XRD pattern displayed in figure $6 \mathrm{a}$ at $2 \theta=33.2^{\circ}$. A dark field image was obtained from one of the extra reflections showing the presence of several elongated crystals aligned along the $[0 \overline{1} 1]_{\mathrm{CVO}}$ direction (figure $7 \mathrm{c}$ ) as depicted in the AFM image (figure 6b).

From this pattern, the epitaxial relationships of the nanostructures related to the (110)STO are:

$[5 \overline{5} 4] \mathrm{Ca}_{3}\left(\mathrm{VO}_{4}\right)_{2} / /[100] \mathrm{CVO}$

$(110) \mathrm{Ca}_{3}\left(\mathrm{VO}_{4}\right)_{2} / /(001) \mathrm{CVO}$

$(2 \overline{2} \overline{5}) \mathrm{Ca}_{3}\left(\mathrm{VO}_{4}\right)_{2} / /(010) \mathrm{CVO}$ 
The mismatches between $\mathrm{CVO}$ and $\mathrm{Ca}_{3}\left(\mathrm{VO}_{4}\right)_{2}$ are equal to $-1.22 \%$ for the first in-plane direction and $-5.72 \%$ for the second one (distances $d_{001}^{\mathrm{CVO}}=5.34 \AA$ and $d_{110}^{\mathrm{Ca} 3(\mathrm{VO} 4) 2}=5.405 \AA$, and $d_{020}^{\mathrm{CVO}}=3.77 \AA$ and $d_{4-4}^{\mathrm{Ca} 3}\left(\mathrm{VO}_{10}\right) 2=3.986 \AA$. Figure $5 \mathrm{~b}$-II shows in-plane projections of the structures. Along this projection, the structure of $\mathrm{Ca}_{3}\left(\mathrm{VO}_{4}\right)_{2}$ appears to be a sequence of puckered atomic planes for which the corresponding lattice distance matches with the (020) lattice distance of CVO.

The larger pyramidal-shaped crystals observed by AFM (figure 6b) were also observed in dark field mode (figures $7 \mathrm{~d}, \mathrm{~g}$ ) after a slight tilt of the sample. Corresponding EDPs were indexed by considering the $[4 \overline{1} 2]$ zone axis of the $\mathrm{Ca}_{3}\left(\mathrm{VO}_{4}\right)_{2}$ phase. Schemes of this orientation relatively to that of the $[100]_{\mathrm{CVO}}$ axis are drawn in figure $7 \mathrm{f}, \mathrm{i}$, showing that two in-plane orientations are observed.

The corresponding epitaxial relationships are:

$$
\begin{aligned}
& {[4 \overline{1} 2] \mathrm{Ca}_{3}\left(\mathrm{VO}_{4}\right)_{2} / /[100] \mathrm{CVO}} \\
& (10 \overline{2}) \mathrm{Ca}_{3}\left(\mathrm{VO}_{4}\right)_{2} / /(01 \overline{1}) \mathrm{CVO} \\
& (10 \overline{2}) \mathrm{Ca}_{3}\left(\mathrm{VO}_{4}\right)_{2} / /(011) \mathrm{CVO}
\end{aligned}
$$



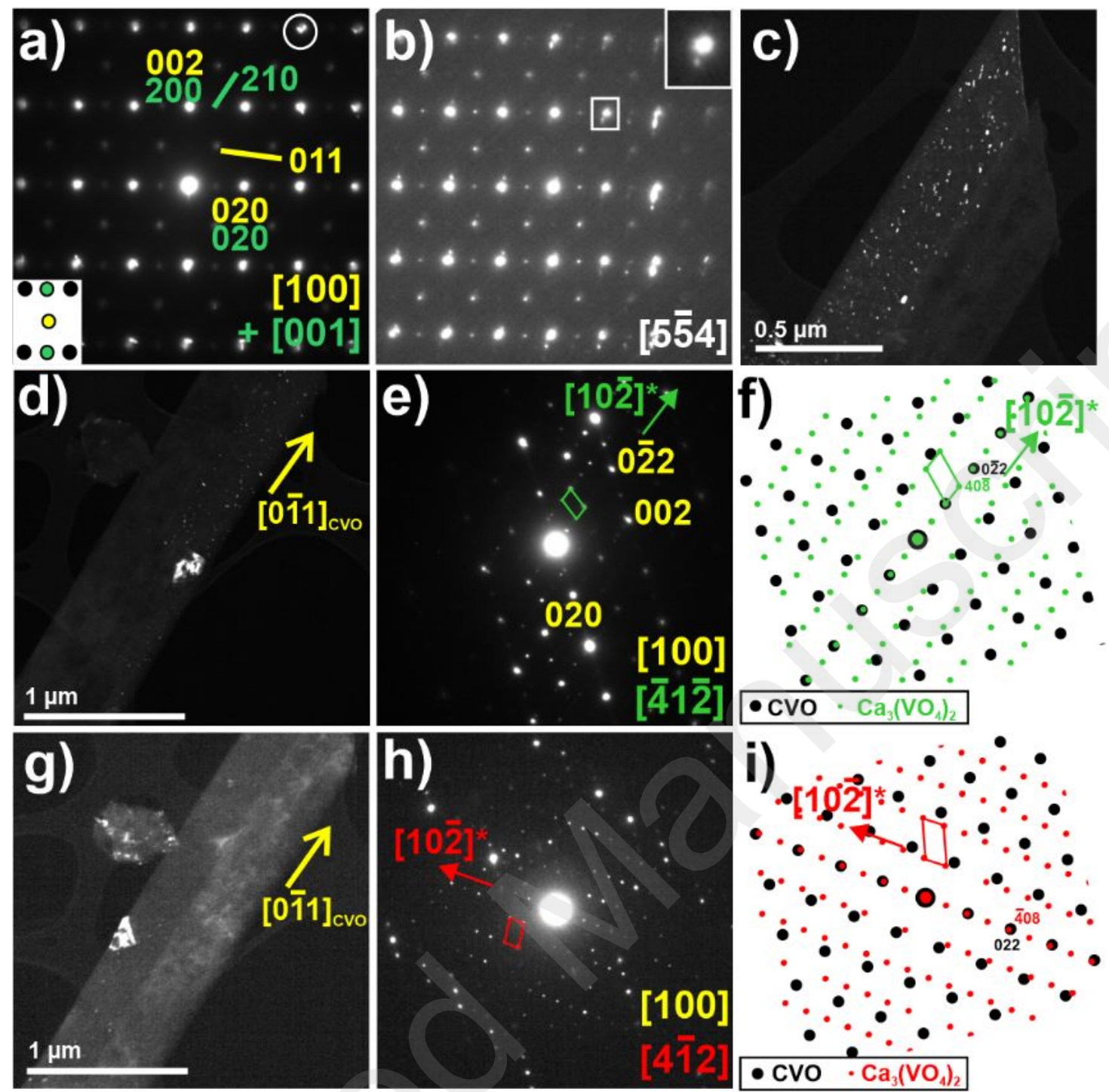

Figure 7. a) EDP along the [100] and [001] zone axes of the CVO film grown on (110)STO showing the presence of two $180^{\circ}$ domains. Inset: scheme of the pattern (black: common reflections, yellow: domain $d 1$, green: $d 2$ ). Some additional reflections due to nanostructures are encircled in white. b) Same as a) taken with a weak off-axis tilt, showing the lattice of the $\mathrm{Ca}_{3}\left(\mathrm{VO}_{4}\right)_{2}$ phase along the [5 $\left.\overline{5} 4\right]$ zone axis. c) Dark field image obtained by selecting one of the $\mathrm{Ca}_{3}\left(\mathrm{VO}_{4}\right)_{2}$ reflections observed in b) and highlighting in white the elongated [5 $\overline{5} 4$ ]-oriented nanostructures. d),g) Dark field images obtained by selecting one of the $\mathrm{Ca}_{3}\left(\mathrm{VO}_{4}\right)_{2}$ reflections observed in e),h)

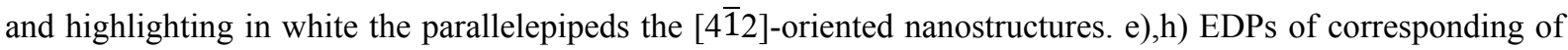
the dark field images shown in $\mathrm{d}, \mathrm{g}$ ) corresponding to the [4 $4 \overline{1} 2]$ zone axis of the phase $\mathrm{Ca}_{3}\left(\mathrm{VO}_{4}\right)_{2}$. f),i) Schemes of the $[100] \mathrm{CVO}$ and $[4 \overline{1} 2]_{\mathrm{Ca} 3(\mathrm{VO}) 2}$ zone axes showing the orientation relationships between both phases. 
The mismatch between $\mathrm{CVO}$ and $\mathrm{Ca}_{3}\left(\mathrm{VO}_{4}\right)_{2}$ is equal to $3.62 \%\left(d_{022}^{\mathrm{CVO}}=2.179 \AA\right.$ and $d_{408}^{\mathrm{Ca} 3}(\mathrm{VO} 4) 2=$ $2.1 \AA$ ). Figure 5 b-II shows in-plane projections of both structures. Along this projection, the structure of $\mathrm{Ca}_{3}\left(\mathrm{VO}_{4}\right)_{2}$ shows the sequence of flat and puckered (102) planes forming parallelepiped similar to those formed in the CVO structure along the [100] direction.

\subsection{Growth of CVO and nanostructures on (111)STO}

Figure 8a displays the XRD patterns of the CVO films grown on (111)STO, showing that CVO has grown on (111)STO with (022) and/or (220) preferential orientations $\left(2 \theta_{022}=\right.$ $41.405^{\circ} ; 2 \theta_{220}=41.527^{\circ}$ ). The pseudo-cubic out-of-plane lattice constant extracted from the XRD data is $3.757 \AA$, again slightly smaller than for the bulk material (3.774 and $3.764 \AA$ ). Finally for the (111)STO substrate, the morphology present several elongated nanowires together with triangular-shaped crystals (with angles in-between 54 and $64^{\circ}$ ) and some dots with a height of $20 \mathrm{~nm}$ (see figure 8b). The derivative topography image (figure 8c) shows that the triangular-shaped crystals are three-fold pyramids with 6 facets.
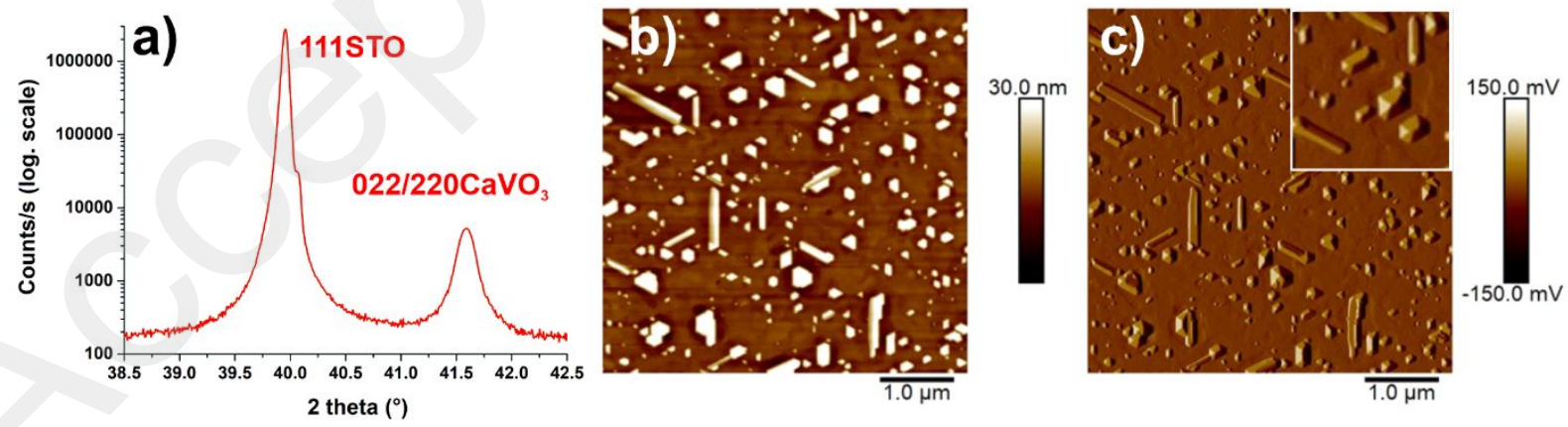

Figure 8. a) XRD patterns of CVO films grown on (111)STO. b) $5 \mu \mathrm{m} \times 5 \mu \mathrm{m}$ AFM morphology images of the film grown on (111)STO. c) $5 \mu \mathrm{m} \times 5 \mu \mathrm{m}$ AFM derivative topography image of the same area. Inset: magnified area. 
The epitaxial relationship of the CVO on (111)STO and the nanostructures have been characterized by electron diffraction. Figure 9a displays the EDP taken along the surface normal of the CVO films grown on (111)STO, corresponding to the [2 $\overline{1} 0] \mathrm{CVO}$ zone axis. The calculated EDP for this orientation is shown on figure 9d. It appears that several additional reflections are present. Some of them can arise from the presence of $\sim 60^{\circ}$ domains of $\mathrm{CVO}$ (see scheme in fig. S6). The mismatch between CVO and STO is equal to $3.3 \%$ for the three domains. When the zone axis is slightly tilted, some other reflections due to the nanostructures are visible as shown in figure $9 \mathrm{~b}$, and depicted by the inset. They correspond to the [5디] $\mathrm{Ca}_{3}\left(\mathrm{VO}_{4}\right)_{2}$ zone axis, which is drawn in figure 9e. This pattern displays a pseudo-hexagonal array of reflections. Nevertheless, comparison between experimental and calculated patterns indicates that some experimental reflections are due to another orientation, namely the [001] $\mathrm{Ca}_{3}\left(\mathrm{VO}_{4}\right)_{2}$ zone axis, schemed in the figure $9 \mathrm{f}$, which is a perfect hexagonal array. 

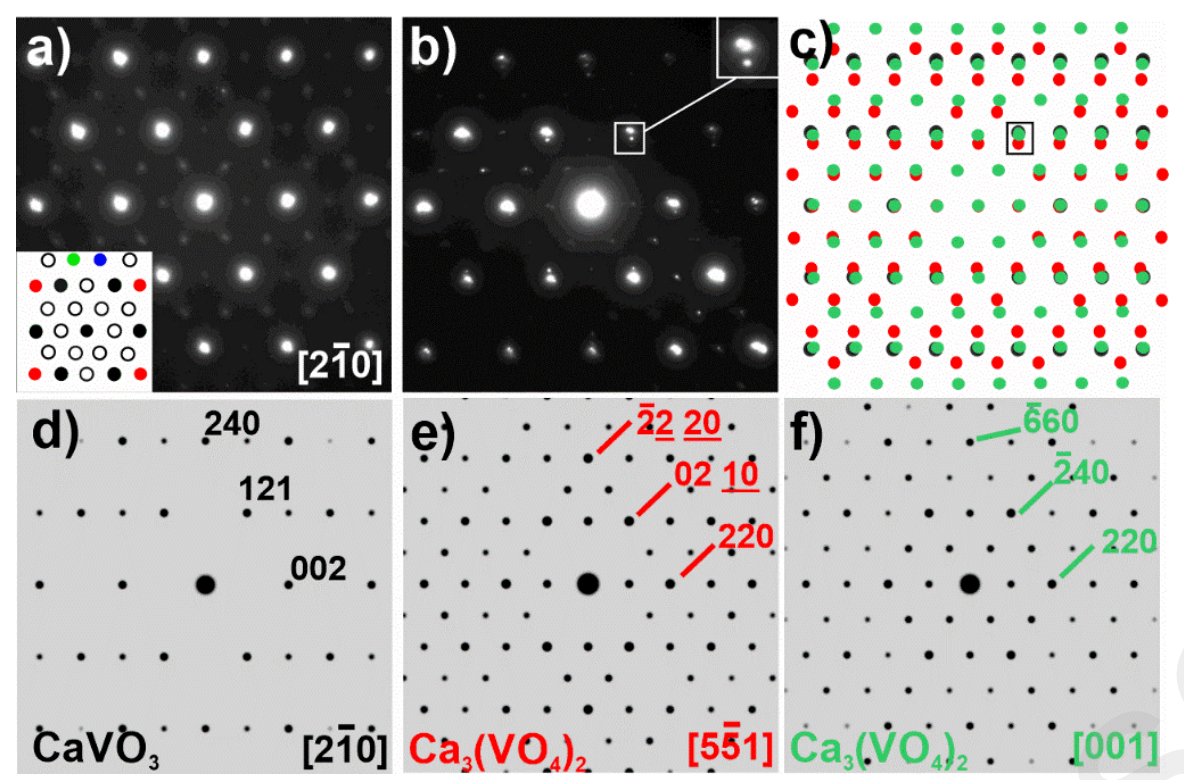

Figure 9. EDP along the $[2 \overline{1} 0]$ zone axis of the CVO film grown on (111)STO showing the presence of three $60^{\circ}$ domains. Inset: scheme of the pattern (black: common reflections, red: domain $d 1$, green: $d 2$; blue: $d 3$, empty circles: double-diffraction effect. b) Same as a) taken with a weak off-axis tilt, showing the lattice of the $\mathrm{Ca}_{3}\left(\mathrm{VO}_{4}\right)_{2}$ phase along the [551] and [001] zone axes. Some additional reflections due to nanostructures are encircled in white. c) Scheme of the experimental EDP displayed in b): black: CVO reflections, red: reflections of the $\mathrm{Ca}_{3}\left(\mathrm{VO}_{4}\right)_{2}$ phase along the [551] zone axis, green: reflections of the $\mathrm{Ca}_{3}\left(\mathrm{VO}_{4}\right)_{2}$ phase along the [001] zone axis. d) Scheme of the CVO [2 $\overline{1} 0]$ zone axis. e) Scheme of the $\mathrm{Ca}_{3}\left(\mathrm{VO}_{4}\right)_{2}[5 \overline{5} 1]$ zone axis. f) Scheme of the $\mathrm{Ca}_{3}\left(\mathrm{VO}_{4}\right)_{2}$ [001] zone axis.

Therefore, two out-of-plane orientations for the $\mathrm{Ca}_{3}\left(\mathrm{VO}_{4}\right)_{2}$ phase on (110)CVO have been observed by EDP, which is in perfect agreement with AFM images (on figure $8 b$ ). The $[5 \overline{5}$ 1] orientation corresponds to the elongated nanostructures (3 variants), and the [001] orientation corresponds to the triangular nanostructures. Figure S7 displays the bright field and dark field images of the film showing the 3 in-plane orientations at $60^{\circ}$ from each other for the elongated nanostructures (figure S7c,d,e), and the triangular-shaped crystals of the second orientation (figure S7f). The figure 5c displays these two orientations in the real space relatively to the subjacent (110)CVO. Along the [55̄1] orientation, the structure displays puckered planes that 
are disposed almost hexagonally, while along the 6-fold axis [001] orientation, the planes are aligned along a perfect hexagon.

The epitaxial relationships for the first orientation are:

$[5 \overline{5} 1] \mathrm{Ca}_{3}\left(\mathrm{VO}_{4}\right)_{2} / /[2 \overline{1} 0] \mathrm{CVO}$

$(110) \mathrm{Ca}_{3}\left(\mathrm{VO}_{4}\right)_{2} / /(001) \mathrm{CVO}$

$(\overline{1} 110) \mathrm{Ca}_{3}\left(\mathrm{VO}_{4}\right)_{2} / /(120) \mathrm{CVO}$

where lattice distances $d_{001}^{\mathrm{CVO}}=5.34 \AA$ and $d_{110}^{\mathrm{Ca} 3(\mathrm{VO} 4) 2}=5.405 \AA$ (mismatch: $-1.22 \%$ ), and $d_{120}^{\mathrm{CVO}}=$ $3.076 \AA$ and $d_{-1110}^{\mathrm{Ca} 3\left(\mathrm{VO}^{2}\right) 2}=3.523 \AA$ (mismatch: $\left.-14.53 \%\right)$. Since the $(001) \mathrm{CVO}$ planes are equivalent to the (121) and $(12 \overline{1}) \mathrm{CVO}$ planes, there exist actually 3 in-plane orientations at $60^{\circ}$ from each other for the elongated nanostructures, namely the above mentioned one and (110) $\mathrm{Ca}_{3}\left(\mathrm{VO}_{4}\right)_{2} / /(121) \mathrm{CVO}$ and $\left.(110) \mathrm{Ca}_{3}\left(\mathrm{VO}_{4}\right)_{2} / /(12 \overline{1})\right) \mathrm{CVO}$. These in-plane orientations for the elongated nanostructures are observed in the AFM image (fig. 8b).

The epitaxial relationships for the second orientation are:

$[001] \mathrm{Ca}_{3}\left(\mathrm{VO}_{4}\right)_{2} ; / /[2 \overline{1} 0] \mathrm{CVO}$

$(110) \mathrm{Ca}_{3}\left(\mathrm{VO}_{4}\right)_{2} / /(001) \mathrm{CVO}$

$(\overline{1} 10) \mathrm{Ca}_{3}\left(\mathrm{VO}_{4}\right)_{2} / /(120) \mathrm{CVO}$

where lattice distances $d_{001}^{\mathrm{CVO}}=5.34 \AA$ and $d_{110}^{\mathrm{Ca} 3(\mathrm{VO} 4) 2}=5.405 \AA$ (mismatch: $-1.22 \%$ ), and $d_{120}^{\mathrm{CVO}}=$ $3.076 \AA$ and $d_{-330}^{\mathrm{Ca} 3(\mathrm{VO}))^{2}}=3.12 \AA$ (mismatch: $-1.43 \%$ ). The angle between the $[\overline{5} 52]$ and the $[\overline{5} 5$ 1] directions is equal to $61.2^{\circ}$, close to the angle value for a cubic phase between [100] and [111] directions $\left(54.74^{\circ}\right)$, therefore reflecting again the presence of a pseudo-cubic sub-unit in the $\mathrm{Ca}_{3}\left(\mathrm{VO}_{4}\right)_{2}$ structure. This is the reason why we observe all these elongated nanostructures on the different orientations of the CVO matrix. Moreover, different nanostructures can also 
emerge with different shapes (pyramids or triangular-shaped crystals) which are related to other possible epitaxial relationships.

\subsection{PFM measurements of CVO and nanostructures with the different orientations}

Vertical PFM measurements have been performed on the nanostructures and the CVO matrix (see figure 10). For all the orientations, piezoelectric activity of the matrix is considered as inexistent, which is expected due to its metallic behavior. At the contrary, for the (100)STO on the nanostructures, localized areas are showing a non-zero piezoresponse (bright areas on figure 10a) and a non-noisy phase (figure 10b). In the case of (111)STO, the piezoresponse is not homogeneous within the grain. The PFM phase is clearly defined as we can see on the bright areas of figure 10d. Nevertheless, the measurement is hampered by the overall conductivity of the sample (matrix and nanostructures) and the results have to be considered with care in both type of nanostructures elongated and hexagonal one. Finally for (110)STO, PFM were investigated on both type of nanostructures. Pyramidal one shows a very low amplitude (dark contrast in the PFM image of the diamond-like structure in figure 10e), comparable to the remaining part of the flat CVO sublayer, where the piezoelectric activity is absent. At the contrary, the elongated nanostructures show a non-ambiguous piezoelectric activity (bright areas on the amplitude image in figure 10-f). The phase of the PFM signal is also well defined on elongated grains whereas the phase is noisy on pyramidal ones (see figure 10-f). From PFM images, it is obvious that the detected piezoelectric activity strongly depends on the type of grains and therefore on their orientations. According to Glass et al. the polarization of $\mathrm{Ca}_{3}\left(\mathrm{VO}_{4}\right)_{2}$ is lying along $\mathrm{c}$ axis ${ }^{2}$. Therefore, the vertical PFM response depends on the nanostructure orientation relatively to the substrate normal. The figure S8 schematizes the 
orientation of the [001] direction relatively to the normal when the nanostructures are out-of-

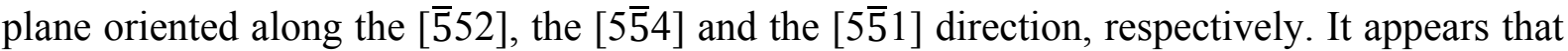
the polarization of the [5 $\overline{5} 4]$ oriented nanostructures (grown on (110) STO) is the closest to the substrate normal with an angle of $31.5^{\circ}$, while the two others directions presents an angle of $50^{\circ}([\overline{5} 52])$ and $69^{\circ}([5 \overline{5} 1])$ to the normal of the substrate. This explains the clear piezoelectric activity observed for the $[5 \overline{5} 4]$ nanostructures.
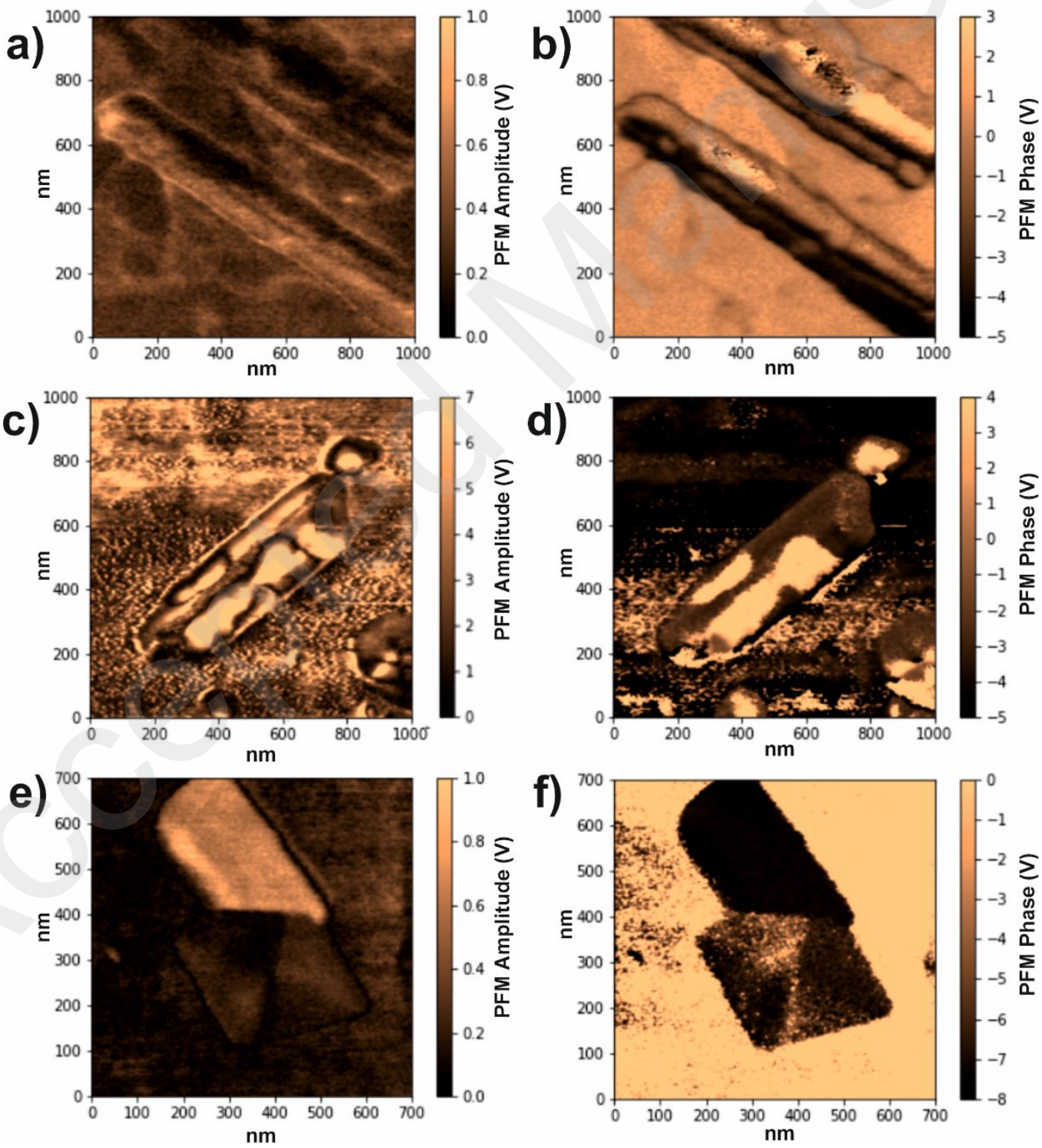
Figure 10. PFM measurements amplitude (a) and phase (b) of nanostructures grown on (100)STO (1 $\mu \mathrm{m} \times 1 \mu \mathrm{m})$, amplitude (c) and phase (d) of nanostructures grown on (111)STO (1 $\mu \mathrm{m}$ x $1 \mu \mathrm{m})$, amplitude (e) and phase (f) of nanostructures grown on (110)STO $(0.7 \mu \mathrm{m} \times 0.7 \mu \mathrm{m})$ : on an elongated and a pyramidal structure.

Attempts to switch the apparent polarization for all the different orientations have been unsuccessful. This can be explained by a strong coercive field not reachable with our PFM device. The same conclusion has been drawn in the case of single crystal where no current switching peaks have been observed even at $150 \mathrm{kV} / \mathrm{cm}^{2,26}$. The other possibility is the leaky character of the nanostructures, which prevents the observation of hysteresis loops. Therefore, it is difficult to conclude if the contrast in PFM images may arise from piezoelectricity or from ionic conduction if applicable.

\section{Conclusions}

Oxidation of the surface of $\mathrm{CaVO}_{3}$ films leads to the growth of the orthovanadate $\mathrm{Ca}_{3}\left(\mathrm{VO}_{4}\right)_{2}$ phase in the form of nanostructures. Orientations of these nanostructures depend on the orientation of subjacent $\mathrm{SrTiO}_{3}$ substrate and therefore of the orientation of the CVO matrix. Complex epitaxial relationships were determined by an accurate TEM and EDP analysis for all the observed nanostructure variants, with different crystal shapes according to the out-of-plane and in-plane orientations: On (100)STO, the $\mathrm{Ca}_{3}\left(\mathrm{VO}_{4}\right)_{2}$ phase grows as elongated nanostructures along the [552] out-of-plane direction with two equivalent variants forming a $90^{\circ}$ angle. On (110)STO, the $\mathrm{Ca}_{3}\left(\mathrm{VO}_{4}\right)_{2}$ phase grows as i) elongated nanostructures along the

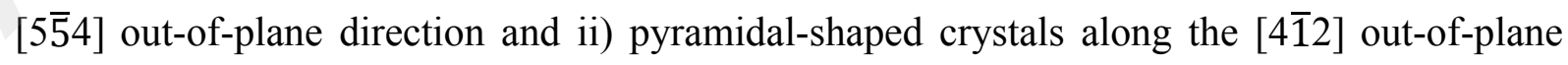
direction. On (111)STO, the $\mathrm{Ca}_{3}\left(\mathrm{VO}_{4}\right)_{2}$ phase grows as i) elongated nanostructures along the [5히] out-of-plane direction (3 variants) and ii) hexagonal-shaped crystals along the [001] out- 
of-plane direction. In terms of piezoelectric properties, the elongated nanostructure with the out-of-plane [554] orientation shows the most promising results with a clear piezoresponse. This orientation corresponds to the epitaxy on $\mathrm{CVO}$ of a $\mathrm{Ca}_{3}\left(\mathrm{VO}_{4}\right)_{2}$ rectangular crystallographic sub-cell of the same dimensions of the (110)CVO cell. In perspective, different parameters such as temperature, time and oxygen pressure during the annealing process will be studied in order to tune the size and density of the nanostructures. These results open the way to large scale selforganized nanostructured templates with a morphological control as function of the substrate orientation. Therefore, this methodology presents an interesting alternative - with one step process - to the lithography or multistep deposition approaches.

\section{Supporting Information}

XRD of CVO films with different orientations, schemes of the different CVO domains on STO, TEM bright field micrographs of CVO film, EELS and EFTEM measurements on CVO film.

\section{Acknowledgements}

Transmission Electron Microscopy was performed on ScanMAT facilities platforms (UMS 2001, University of Rennes 1-CNRS). The authors acknowledge the French Agence Nationale de la Recherche (ANR) (ANR-17-CE08-0012) in the framework of the POLYNASH project for financial support. Dr André Perrin is warmly acknowledged for fruitful discussions. 


\section{References}

(1) Obradors, X.; Puig, T.; Gibert, M.; Queralto, A.; Zabaleta, J.; Mestres, N. Chemical Solution Route to Self-Assembled Epitaxial Oxide Nanostructures. Chem. Soc. Rev. 2014, 43 (7), 22002225. https://doi.org/10.1039/c3cs60365b.

(2) Glass, A.; Abrahams, S.; Ballman, A.; Loiacono, T. H. Calcium Ortho-Vanadate, Ca3(VO4)2 New High-Temperature Ferroelectric. Ferroelectrics 1978, 17 (3-4), 579-582. https://doi.org/10.1080/00150197808236782.

(3) Zhang, L.; Zhou, Y.; Guo, L.; Zhao, W.; Barnes, A.; Zhang, H.-T.; Eaton, C.; Zheng, Y.; Brahlek, M.; Haneef, H. F.; Podraza, N. J.; Chan, M. H. W.; Gopalan, V.; Rabe, K. M.; Engel-Herbert, R. Correlated Metals as Transparent Conductors. Nat. Mater. 2016, 15 (2), 204-+. https://doi.org/10.1038/NMAT4493.

(4) Berini, B.; Demange, V.; Bouttemy, M.; Popova, E.; Keller, N.; Dumont, Y.; Fouchet, A. Control of High Quality SrVO3 Electrode in Oxidizing Atmosphere. Adv. Mater. Interfaces 2016, 3 (18), 1600274. https://doi.org/10.1002/admi.201600274.

(5) Mirjolet, M.; Vasili, H. B.; López-Conesa, Ll.; Estradé, S.; Peiró, F.; Santiso, J.; Sánchez, F.; Machado, P.; Gargiani, P.; Valvidares, M.; Fontcuberta, J. Independent Tuning of Optical Transparency Window and Electrical Properties of Epitaxial SrVO3 Thin Films by Substrate Mismatch. Adv. Funct. Mater. 2019, 29 (37), 1904238. https://doi.org/10.1002/adfm.201904238.

(6) Eaton, C.; Moyer, J. A.; Alipour, H. M.; Grimley, E. D.; Brahlek, M.; LeBeau, J. M.; EngelHerbert, R. Growth of SrVO3 Thin Films by Hybrid Molecular Beam Epitaxy. J. Vac. Sci. Technol. A 2015, 33 (6), 061504. https://doi.org/10.1116/1.4927439.

(7) Brown, J. J. Phase Equilibria in the System SrO-CdO-V2O5. J. Am. Ceram. Soc. 1972, 55 (10), 500-503. https://doi.org/10.1111/j.1151-2916.1972.tb13415.x.

(8) Yaremchenko, A. A.; Brinkmann, B.; Janssen, R.; Frade, J. R. Electrical Conductivity, Thermal Expansion and Stability of $\mathrm{Y}$ - and Al-Substituted $\mathrm{SrVO} 3$ as Prospective SOFC Anode Material. Solid State lon. 2013, 247-248, 86-93. https://doi.org/10.1016/j.ssi.2013.06.002.

(9) Cheng, Z.; Zha, S.; Aguilar, L.; Liu, M. Chemical, Electrical, and Thermal Properties of Strontium Doped Lanthanum Vanadate. Solid State Ion. 2005, 176 (23-24), 1921-1928. https://doi.org/10.1016/j.ssi.2005.05.009.

(10) García-Jaca, J.; Pizarro, J. L.; Larramendi, J. I. R.; Lezama, L.; Arriortua, M. I.; Rojo, T. Synthesis, Crystal Structure, Spectroscopic and Magnetic Properties of Strontium Oxovanadium(IV) Tartrate: Molecular Precursor for SrVO3. J. Mater. Chem. 1995, 5 (2), 277-283. https://doi.org/10.1039/JM9950500277.

(11) García-Jaca, J.; Larramendi, J. I. R.; Insausti, M.; Arriortua, M. I.; Rojo, T. Synthesis, Crystal Structure and Transport Properties of a New Non-Stoichiometric CaVO3 $+\delta$ Phase. J. Mater. Chem. 1995, 5 (11), 1995-1999. https://doi.org/10.1039/JM9950501995. 
(12) Eaton, C.; Lapano, J.; Zhang, L.; Brahlek, M.; Engel-Herbert, R. Self-Regulated Growth of CaVO3 by Hybrid Molecular Beam Epitaxy. J. Vac. Sci. Technol. A 2017, 35 (6), 061510. https://doi.org/10.1116/1.5001341.

(13) Macias, J.; Yaremchenko, A. A.; Frade, J. R. Redox Transitions in Strontium Vanadates: Electrical Conductivity and Dimensional Changes. J. Alloys Compd. 2014, 601, 186-194. https://doi.org/10.1016/j.jallcom.2014.02.148.

(14) Lichtensteiger, C. InteractiveXRDFit: A New Tool to Simulate and Fit X-Ray Diffractograms of Oxide Thin Films and Heterostructures. J. Appl. Crystallogr. 2018, 51, 1745-1751. https://doi.org/10.1107/S1600576718012840.

(15) Garcia-Jaca, J.; Mesa, J. L.; Insausti, M.; Larramendi, J. I. R.; Arriortua, M. I.; Rojo, T. Synthesis, Crystal Structure, Stoichiometry and Magnetic Properties of (Ca1-XSrx)VO3. Mater. Res. Bull. 1999, 34 (2), 289-301. https://doi.org/10.1016/S0025-5408(99)00002-1.

(16) Liberati, M.; Chopdekar, R. V.; Mehta, V.; Arenholz, E.; Suzuki, Y. Epitaxial Growth and Characterization of CaVO3 Thin Films. J. Magn. Magn. Mater. 2009, 321 (18), 2852-2854. https://doi.org/10.1016/j.jmmm.2009.04.037.

(17) Gu, M.; Laverock, J.; Chen, B.; Smith, K. E.; Wolf, S. A.; Lu, J. Metal-Insulator Transition Induced in CaVO3 Thin Films. J. Appl. Phys. 2013, 113 (13), 133704. https://doi.org/10.1063/1.4798963.

(18) Scola, J.; Boullay, P.; Noun, W.; Popova, E.; Dumont, Y.; Fouchet, A.; Keller, N. Microstructure and Self-Exchange Coupling in a YFeO3 Film. J. Appl. Phys. 2011, 110 (4), 043928. https://doi.org/10.1063/1.3626749.

(19) Copie, O.; Varignon, J.; Rotella, H.; Steciuk, G.; Boullay, P.; Pautrat, A.; David, A.; Mercey, B.; Ghosez, P.; Prellier, W. Chemical Strain Engineering of Magnetism in Oxide Thin Films. Adv. Mater. 2017, 29 (22), 1604112. https://doi.org/10.1002/adma.201604112.

(20) Gopal, R.; Calvo, C. Structure of Ca3(VO4)2. Z. Krist. 1973, 137 (1), 67-85. https://doi.org/10.1524/zkri.1973.137.1.67.

(21) Germanicus, R. C.; Bourlier, Y.; Notot, V.; Bérini, B.; Demange, V.; Berthe, M.; Boileau, A.; Euchin, M.; Dumont, Y.; Aureau, D.; Fregnaux, M.; Grandidier, B.; Lüders, U.; David, A.; Prellier, W.; Biadala, L.; Fouchet, A. Three Dimensional Resistance Mapping of Self-Organized Sr3V2O8 Nanorods on Metallic Perovskite SrVO3 Matrix. Appl. Surf. Sci. 2020, 510, 145522. https://doi.org/10.1016/j.apsusc.2020.145522.

(22) Carrillo-Cabrera, W.; Von Schnering, H. Crystal Structure Refinement of Strontium TetraoxoVanadate(V), Sr3(VO4)2. Z. Krist. 1993, 205, 271-276. https://doi.org/10.1524/zkri.1993.205.Part-2.271.

(23) Fitting Kourkoutis, L.; Hotta, Y.; Susaki, T.; Hwang, H. Y.; Muller, D. A. Nanometer Scale Electronic Reconstruction at the Interface between LaVO3 and LaVO4. Phys. Rev. Lett. 2006, 97 (25), 256803. https://doi.org/10.1103/PhysRevLett.97.256803.

(24) Laffont, L.; Wu, M. Y.; Chevallier, F.; Poizot, P.; Morcrette, M.; Tarascon, J. M. High Resolution EELS of Cu-V Oxides: Application to Batteries Materials. Micron 2006, 37 (5), 459-464. https://doi.org/10.1016/j.micron.2005.11.007.

(25) Moreno, C.; Abellán, P.; Hassini, A.; Ruyter, A.; del Pino, A. P.; Sandiumenge, F.; Casanove, M.J.; Santiso, J.; Puig, T.; Obradors, X. Spontaneous Outcropping of Self-Assembled Insulating Nanodots in Solution-Derived Metallic Ferromagnetic La0.7Sr0.3MnO3 Films. Adv. Funct. Mater. 2009, 19 (13), 2139-2146. https://doi.org/10.1002/adfm.200900095.

(26) Ning, H.; Yan, H.; Reece, M. J. A High Curie Point Ferroelectric Ceramic Ca3(VO4)2. Ferroelectrics 2015, 487 (1), 94-100. https://doi.org/10.1080/00150193.2015.1070653. 
TOC :

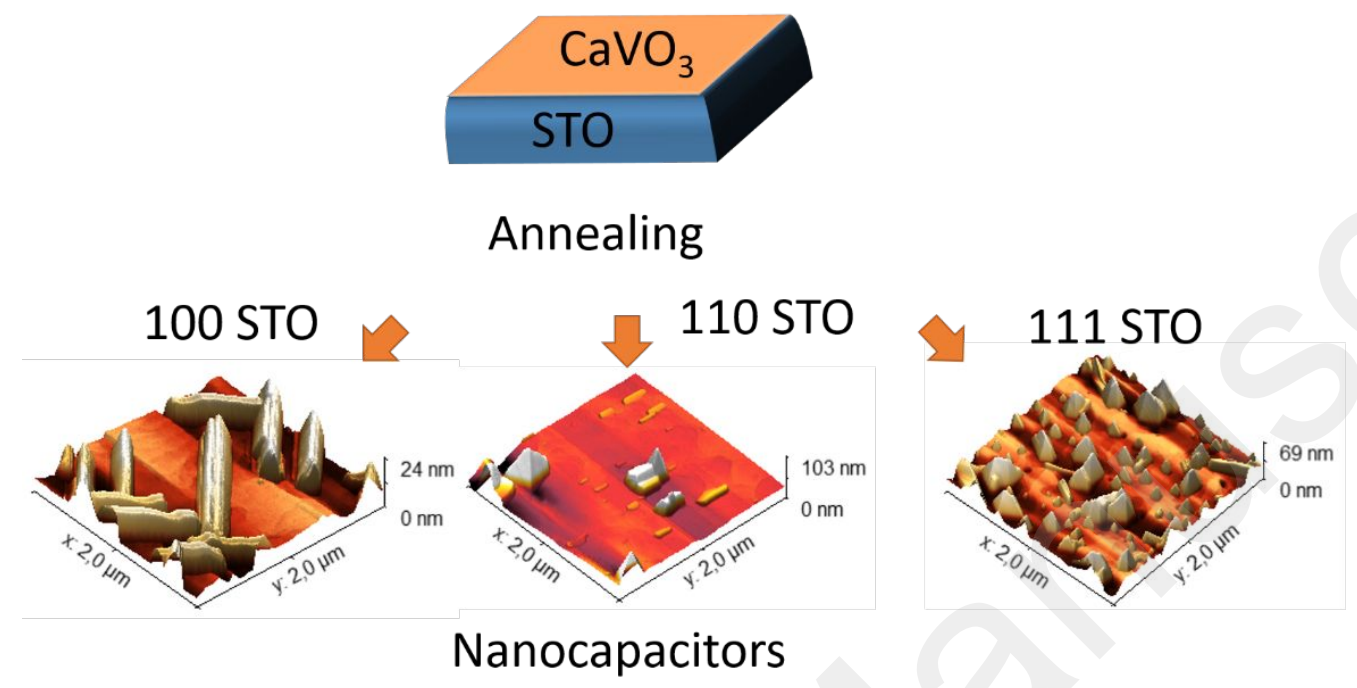

